\title{
DISTRIBUTION AND SPATIAL PATTERN ANALYSIS ON MALNUTRITION CASES: A CASE STUDY IN PONTIANAK CITY
}

\author{
Agus Fitriangga ${ }^{1}$, Gerry Albilardo² and Muhammad Pramulya ${ }^{3}$ \\ 1Department of Community Medicine, Faculty of Medicine, Univesitas Tanjungpura, Indonesia, PO Box 78124 \\ ${ }^{2}$ Third-year Medical Student, Faculty of Medicine, Universitas Tanjungpura, Indonesia, PO Box 78124 \\ ${ }^{3}$ Department of Regional Planning, Faculty of Agriculture, Universitas Tanjungpura, Indonesia, PO Box 78124
}

Corresponding author: Agus Fitriangga

Email Address : afitriangga@medical.untan.ac.id

\begin{abstract}
Based on the Basic Health Research (Riskesdas) in 2018, malnutrition cases in West Kalimantan reached 23.8 percent. In 2015, Pontianak City documented 27 cases of malnutrition. Then, the cases increased in 2016 and 2017 as many as 29 and 41 cases. The utilization of Geographic Information System (GIS) is required as a method for public health surveillance and monitoring. This study aims to analyze the distribution of malnutrition cases based on several clinical and non-clinical factors using GIS between 2016 to 2017. The dependent variable was malnutrition cases and the independent variables included household income level, parent's educational level, comorbidities factors, and distance to the primary health care service. A total of 65 cases of malnutrition in Pontianak City were collected from six subdistricts in Pontianak City. This research was a cross-sectional study. The results showed that of 65 cases of malnutrition occurred on under 5-year-old children in Pontianak in 2016-2017, malnutrition cases taking place in East Pontianak sub-district were 29 cases (44.6\%). In addition, malnutrition with clinical symptoms was reported 63 cases (96.9\%), while the distance from home to primary health care less than $1 \mathrm{~km}$ was 32 cases (49.23\%). The study also revealed that malnutrition with comorbidities were $78,5 \%$. Finally, household income levels with malnutrition were below Pontianak regional minimum wage (Rp 2,515,000/month or \$176,88). The mapping of malnutrition cases using Geographic Information Systems can facilitate the nutrition programmer in Pontianak City Health Office and Public Health Centre in intervening the social determinant of health to overcome malnutrition.
\end{abstract}

Keywords: Mapping, Malnutrition Cases, spatial pattern, under 5-year-old children, Pontianak City

\section{INTRODUCTION}

Malnutrition cases are still a problem in several countries. Asian countries report $70 \%$ of malnutrition cases, followed by Africa with $26 \%$ cases and $4 \%$ in Latin America. It was recorded that one of three children in the world dies every year due to poor nutritional quality ${ }^{1}$. The Ministry of Health of the Republic of Indonesia showed that at least 3.5 million children die every year due to malnutrition and poor food quality, supported by malnutrition while still in the womb. This condition can damage a child's health that can not be restored when the child is growing up ${ }^{1}$.

According to Health Basic Research (Riskesdas) data in Indonesia, in 2013, there were $19.6 \%$ cases of children under 5 years old suffering from malnutrition. This figure increases compared to Riskesdas data in 2010 which was $17.9 \%$ and Riskesdas 2007 was $18.4 \%^{2}$. West Kalimantan has decreased the prevalence of malnutrition of children aged $0-59$ which is $6.67 \%$ in 2016 to $6.50 \%$ in $2017^{3}$ Based on the results of the nutrition program report of the West Kalimantan Provincial Health Office in 2016, from all districts/cities there were 401 cases of malnutrition. This figure was obtained from the case report based on clinical signs of malnutrition cases. In 2017, there were 392 malnutrition cases ${ }^{4}$. Meanwhile in Pontianak City, in 2016, there were 29 cases of malnutrition and it increased in 2017 as 41 cases $^{5}$.

Spatial analysis using Geographic Information Systems (GIS) is one of the important methods for public health surveillance and monitoring. This is because the function of GIS in the health sector can produce a spatial picture of health events, analyze relationships between locations, environments, and disease events ${ }^{6}$.

Previous studies have indicated the importance of GIS in mapping malnutrition cases. Murni Su et al, for instance, showed that the utilization of remote sensing data such as land use, NVDI, soil moisture DEM, and flood-prone areas have significantly proved to be useful in identifying environmental factors contributing to malnutrition ${ }^{7}$. Ali Almasi showed that the prevalence of stunting, wasting, and overweight in children under 5-year-old was not accidental and has emerged in the cluster form based on a regular occurrence in countries around the world $^{8}$. Meanwhile, E Mohammed's research showed thematic maps that present the variation of the distribution of Severe Acute Malnutrition 
children in Khartoum State, influenced by several factors such as socioeconomic and environmental realities of Khartoum State?

Therefore, this study attempts to analyze the distribution of malnutrition cases by using GIS. The distribution map of malnutrition cases is also possible to show the information of location in each administrative region in Pontianak City between 2016 to 2017 by patient's names and addresses.

\section{METHODS}

This cross-sectional study was conducted in Pontianak City, West Kalimantan Province from January 2019 to October 2019. The population in this study were all under 5 -year-old children who suffered malnutrition. They were registered in the Pontianak City Health Office between 2016 to 2017. Further, 65 malnutrition children who have received treatments by using total sampling techniques were selected to participate as a sample in this study. The instruments used in this study were location maps, Global Positioning System (GPS), photographic tools, and ArcGIS.

\section{Data Collection}

Demographic data of malnutrition cases reported at Pontianak Health Office in the years of 2016 and 2017 contains (1) Location, (2) number of cases, (3) household characteristics, and (4) clinical data recorded. During the years surveyed, a total of 65 cases were reported throughout Pontianak City selected for this study. Latitude and longitude coordinates of patients' locality were extracted from the data collection to perform distribution and spatial analysis.

\section{Statistical Analysis}

Statistical analysis is used to identify and confirm spatial patterns, such as the center of a group of features, the directional trend, and whether features form clusters. It also classifies and symbolizes the data which can obscure or overemphasize patterns. Statistical functions analyze the underlying data and measures that can be used to confirm the existence and strength of the pattern ${ }^{10}$. Thus, the statistical analyses in this study will help to provide answers for linking the distribution pattern of malnutrition cases with household characteristics.

Meanwhile, geographical distribution is performed to measure a set of features for calculation of value which represents a characteristic of the distribution, such as the center, orientation, or compactness ${ }^{10}$. This study focused on two methods: Spatial distribution and spatial distribution pattern analysis. The spatial distribution included spatial mean center, standard distance, and directional distribution analysis. Spatial distribution pattern analysis is the average nearest neighbor method. Mapping of the malnutrition epidemiology distribution trend identified a relationship with specific physical characteristics. Further, distribution and pattern analysis were conducted to understand whether there were any dominant distributions and patterns for the malnutritiron ${ }^{11}$, 12. Pattern distribution details were minimized using pattern analysis. The clustered pattern showed there was a factor that causes malnutrition epidemiology in that area.

\section{Spatial Mean Center}

The spatial mean center is the average $x$ and $y$ coordinates of all features in the study area. It is useful to detect changes in distribution or to compare features of distribution. This analysis showed leaning-centered phenomena, especially, to visualize the means of malnutrition cases reported in Pontianak City. The spatial mean center aims to study changes in distribution detection to compare the type and feature of distributions. The spatial mean center is able to create a new feature point classification where every feature represents the mean center. The mean of $x$ and $y$ showed the value of mean center which means that the dimensional field was included as the product of features.

The mean center is calculated as follows:

$$
\begin{gathered}
\bar{X}=\frac{\sum_{i=1}^{n} x_{i}}{n} \\
\bar{Y}=\frac{\sum_{i=1}^{n} y_{i}}{n}
\end{gathered}
$$

where $x_{i}$ and $y_{i}$ are coordinates for $i$, and $n$ is the total number of the features.

The weighted mean is calculated as follows:

$$
\begin{aligned}
& \overline{\mathrm{X}} \mathrm{w}=\frac{\sum_{\mathrm{i}=1}^{\mathrm{n}} \mathrm{w}_{\mathrm{i}} \mathrm{x}_{\mathrm{i}}}{\sum_{\mathrm{i}=1}^{\mathrm{n}} \mathrm{w}_{\mathrm{i}}} \\
& \overline{\mathrm{Y}} \mathrm{w}=\frac{\sum_{\mathrm{i}=1}^{\mathrm{n}} \mathrm{w}_{\mathrm{i}} \mathrm{y}_{\mathrm{i}}}{\sum_{\mathrm{i}=1}^{\mathrm{n}} \mathrm{W}_{\mathrm{i}}}
\end{aligned}
$$

where $w_{i}$ is the weigh on characteristic $i$.

The method to calculate center for three dimensions is the $z$ attribute for every feature:

$$
\begin{aligned}
& \bar{Z}=\frac{\sum_{\mathrm{i}=1}^{\mathrm{n}} \mathrm{z}_{\mathrm{i}}}{\mathrm{n}} \\
& \overline{\mathrm{Z}} \mathrm{W}=\frac{\sum_{\mathrm{i}=1}^{\mathrm{n}} \mathrm{W}_{\mathrm{i}} \mathrm{z}_{\mathrm{i}}}{\sum_{\mathrm{i}=1}^{\mathrm{n}} \mathrm{W}_{\mathrm{i}}}
\end{aligned}
$$

\section{Standard Distant}

Standard distant measures distribution density, which provides a single value, represents the distribution around the mean center. The scatter of points around the center needs measurement. The value is the distance represented by deviations. Therefore, measures of spatial dispersion give information about malnutrition cases around a center. The expression used is the 
standard distance, which is equivalent to the statistician's standard deviation. The standard distance is a tool used to create a round polygon of points dispersed around a center. In this study, a round of polygon represented dispersed malnutrition cases reported in each year from the mean center ${ }^{10}$.

Standard distant shows a new feature class which includes a round, centered polygon on the mean center (a single mean and a circle for every case). Every round polygon is created with radii that have the same value as the standard distant value. The attribute value for every round polygon is the $x$-coordinate mean-centered polygon, $y$ coordinate mean-centered, and standard distance (radius circle).

Calculation of the standard distance is as follows:

$$
\mathrm{SD}=\sqrt{\frac{\sum_{\mathrm{i}=1}^{\mathrm{n}}(\mathrm{xi}-\overline{\mathrm{X}})^{2}}{\mathrm{n}}+\frac{\sum_{\mathrm{i}=1}^{\mathrm{n}}(\mathrm{yi}-\overline{\mathrm{Y}})^{2}}{\mathrm{n}}}
$$

where $x_{i}$ and $y_{i}$ are the coordinates for feature $i$, $\{\bar{X}, \bar{Y}\}$ show mean center features, and $n$ is equal to the total of feature number.

The weighted standard distance is as follows:

$$
\mathrm{SDw}=\sqrt{\frac{\sum_{\mathrm{i}=1}^{\mathrm{n}} \mathrm{W}_{\mathrm{i}}(\mathrm{xi}-\overline{\mathrm{X}})^{2}}{\sum_{\mathrm{i}=1}^{\mathrm{n}} \mathrm{W}_{\mathrm{i}}}+\frac{\sum_{\mathrm{i}=1}^{\mathrm{n}} \mathrm{W}_{\mathrm{i}}(\mathrm{yi}-\overline{\mathrm{Y}})^{2}}{\sum_{\mathrm{i}=1}^{\mathrm{n}} \mathrm{W}_{\mathrm{i}}}}
$$

where $w_{i}$ is the weigh on feature $i$ and $\{\bar{X} w, \bar{Y} w\}$ indicates the mean center.

\section{Standard Deviational Ellipse}

As a GIS tool for delineating spatial point data, standard deviational Ellipse (SDE) was used to summarize the spatial characteristics of geographical features. The features include the central tendency, dispersion, and directional trends ${ }^{10}$. The common method to measure the trend of one set location is to calculate standard distance separately on axis $x$ and $y$. Both steps determine the ellipse axis while including distribution characteristics. Ellipse is also known as a standard deviational ellipse. It is calculated by the standard deviation from the $\mathrm{x}$-coordinate and $y$-coordinate from the mean center to determine the ellipse axis. Ellipse allows distribution characteristics to go longitudinally and have a certain orientation. Graphing ellipses were used in disease surveillance studies to predict spatial spread trends since the central tendency and dispersion are two principal aspects concerned by epidemiologists ${ }^{13}$.

The calculations are as in Equations $9 a$ and $9 b$ below:

$$
\begin{aligned}
& \text { SDEx }=\sqrt{\frac{\sum_{\mathrm{i}=1}^{\mathrm{n}}\left(\mathrm{x}_{\mathrm{i}}-\overline{\mathrm{x}}\right)^{2}}{\mathrm{n}}} \\
& \text { SDEy }=\sqrt{\frac{\sum_{\mathrm{i}=1}^{\mathrm{n}}\left(\mathrm{y}_{\mathrm{i}}-\overline{\mathrm{y}}\right)^{2}}{\mathrm{n}}}
\end{aligned}
$$

where $x_{i}$ and $y_{i}$ are the coordinates for feature $i$, $\{\bar{X}, \bar{Y}\}$ shows the mean center, and $n$ is the total number of features.

The angle of rotation calculated as Equation (2) below:

$$
\begin{aligned}
& \tan \theta=\frac{A+B}{C} \\
& A=\sum_{i=1}^{n} \bar{x}_{i}^{2}-\sum_{i=1}^{n} \bar{y}_{i}^{2} \\
& \mathrm{~B}=\sqrt{\left(\sum_{\mathrm{i}=1}^{\mathrm{n}} \overline{\mathrm{x}}_{\mathrm{i}}^{2}\right)^{2}-\left(\sum_{\mathrm{i}=1}^{\mathrm{n}} \overline{\mathrm{y}}_{\mathrm{i}}^{2}\right)^{2}} \\
& \mathrm{C}=\sum_{\mathrm{i}=1}^{\mathrm{n}} \overline{\text { xiyi }}
\end{aligned}
$$

where $x i$ and yi deviation derived from $x y$ coordinates from the mean center.

The standard deviation for $\mathrm{x}$ and $\mathrm{y}$-axis are as follows:

$$
\begin{aligned}
& a x=\sqrt{2} \frac{\sqrt{\sum_{\mathrm{i}=1}^{\mathrm{n}}\left(\overline{\mathrm{x}} \mathrm{i} \cos \theta-(\overline{\mathrm{y}} \sin \theta)^{2}\right.}}{\mathrm{n}} \\
& \mathrm{ay}=\sqrt{2} \frac{\sqrt{\sum_{\mathrm{i}=1}^{\mathrm{n}}\left(\overline{\mathrm{x} i} \sin \theta-(\overline{\mathrm{y}} \cos \theta)^{2}\right.}}{\mathrm{n}}
\end{aligned}
$$

Standard deviational ellipse creates a new feature class that includes centered ellipse polygon on the mean center for all characteristics (or for cases when values were defined) ${ }^{10}$. Attribute values from ellipse polygon included standard distance (long and short axis) and ellipse orientation. Orientation represents long axis rotation measured clockwise from noon. In this study, SDE was conducted to analyze quantitatively the orientation of malnutrition cases. It specifically identified to what extent those malnutrition cases might have spread. In addition to that, it also tried to identify the number of standard deviation $(1,2$, or 3$)$. When the features have a normal spatial distribution (which means dense in the center and less dense towards the edge), one standard deviation makes up to $68 \%$ from all centroid input features. Two standard deviations will make up about 95\% from all features and three standard deviations will cover about $99 \%$ of all centroid features.

The spatial distribution pattern mapping was conducted by a pattern analysis using the average nearest neighbor (ANN). The method measures the average distance of each point in the study area to its nearest point. The average distance was compared to the expected average distance. In doing so, an ANN ratio was created, which, was the ratio of observed/expected. If the ratio is less than 1, we can say that the data exhibits a clustered pattern. Meanwhile, a value greater than 1 indicates a dispersed pattern in our data ${ }^{10}$. In this study, this distribution pattern mapping of malnutrition cases was observed, and the shape of the ANN curve as a function of neighbor order could provide insight into the spatial arrangement 
of points relative to one another whether it was clustered, random, or dispersed. ArcMap 10.5 software was used to perform these statistical analyses. The application employed mathematical equations in the software to develop every analysis with different functions.

Dependent Variable is the number of Cases of Malnutrition. Independent Variables, on the other hand, involve household characteristics such as household income level, parent's educational level, and the living distance to Primary health care.

RESULTS
Pontianak City is crossed by the Equator Line at $0^{\circ}$ 02 '24 "north latitude to $0^{\circ} 01^{\prime}$ ' 37" South Latitude and $109^{\circ} 16$ '25 "East Longitude to $109^{\circ} 23^{\prime} 04^{\prime \prime}$ East Longitude. The height of Pontianak City ranges from 0.10 meters to 1.50 meters above sea level. The population in Pontianak City in 2016 was 618,388 consisting of 308,596 male population and 309,792 female population. Meanwhile, in 2017, the number increased to 627,021 comprised of 312,178 male population and 314,843 female population. Most of the population were transmigrants from Java and indigenous people from West Kalimantan.

Table 1 Coverage Area Population and Density of Pontianak City

\begin{tabular}{rlrrr}
\hline \multirow{2}{*}{ Number } & Sub-Districts & $\begin{array}{c}\text { Coverage area } \\
\left(\mathbf{k m}^{2}\right)\end{array}$ & Population & Density $/ \mathbf{k m}^{2}$ \\
\hline $\mathbf{1}$ & City of Pontianak & 15.98 & 124,031 & 7761.64 \\
$\mathbf{2}$ & West Pontianak & 16.47 & 138,949 & 8436.49 \\
$\mathbf{3}$ & South Pontianak & 15.14 & 94,409 & 6235.73 \\
$\mathbf{4}$ & East Pontianak & 8.78 & 93,268 & 10622.78 \\
$\mathbf{5}$ & North Pontianak & 37.22 & 126,597 & 3401.32 \\
$\mathbf{6}$ & Southeast Pontianak & 14.22 & 50,822 & 3573.98 \\
\hline Total & & 107.82 & 628,076 & 5825.77 \\
\hline
\end{tabular}

Table 2. Distribution of Respondent's Characteristics

\begin{tabular}{|c|c|c|}
\hline Variables & Frequency $(\mathrm{N}=65)$ & Percent \\
\hline \multicolumn{3}{|c|}{ 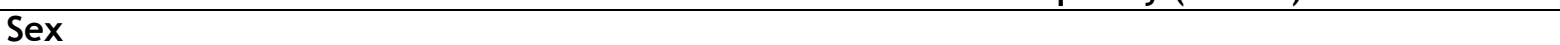 } \\
\hline Men & 39 & 60 \\
\hline Women & 26 & 40 \\
\hline \multicolumn{3}{|l|}{ Age (month) } \\
\hline $0-10$ & 14 & 21.5 \\
\hline $11-20$ & 33 & 50.8 \\
\hline $21-30$ & 7 & 10.8 \\
\hline $31-40$ & 4 & 6.2 \\
\hline $41-50$ & 4 & 6.2 \\
\hline $50-59$ & 3 & 4.6 \\
\hline \multicolumn{3}{|l|}{ Parent's Education } \\
\hline High & 34 & 52.3 \\
\hline Low & 31 & 47.7 \\
\hline \multicolumn{3}{|l|}{ Household Income } \\
\hline$>2,515,000$ IDR $(>\$ 176,88)$ & 44 & 67.7 \\
\hline$<2,515,000$ IDR $(<\$ 176,88)$ & 21 & 32.3 \\
\hline \multicolumn{3}{|l|}{ Comorbidities Diseases } \\
\hline without comorbidities & 14 & 21.5 \\
\hline having comorbidities & 51 & 78.5 \\
\hline \multicolumn{3}{|l|}{ Clinical Symptoms } \\
\hline kwashiorkor & 2 & 3.1 \\
\hline marasmus & 62 & 95.4 \\
\hline marasmus + kwashiorkor & 1 & 1.5 \\
\hline
\end{tabular}




\section{Univariate analysis}

This section discusses the results of the univariate analysis of each variable. Table 2 illustrates the distribution of the characteristics of malnourished patients. The table showed that most of the patients were male by 39 patients $(60 \%) .33$ patients $(50.8 \%$ ) were aged between 11-20 months where more than half of the parental education was high as many as 34 people $(52.3 \%)$. The table also indicated that most of the parents $(67 \%)$ have an income that

was above the regional wage. Among the malnutrition patients, 51 people suffered from comorbidities $(78.5 \%)$. These comorbidities diseases included TB, HIV, acute gastroenteritis, congenital heart disease, anemia, and upper respiratory tract infection. Finally, it was reported that all patients experienced clinical symptoms such as marasmus (62 patients) and kwashiorkor (2 patients) respectively. Additionally, 1 patient suffered from both symptoms.

\section{Bivariate analysis}

According to Table 3, it appears that there was no relationship among the variables of gender, parental education, family income, and clinical symptoms with the incidence of malnutrition, with a $p$-value $>0.05$.

Table 3. Bivariate Analysis

Malnutrition Cases

$95 \% \mathrm{Cl}$

\begin{tabular}{|c|c|c|c|c|c|}
\hline Variables & $\begin{array}{c}\text { without } \\
\text { comorbiditiesn(\%) }\end{array}$ & $\begin{array}{c}\text { having } \\
\text { comorbidities } \\
\mathrm{n}(\%)\end{array}$ & P-Value & Lower & Upper \\
\hline \multicolumn{6}{|l|}{ Sex } \\
\hline Men & $7(10.77$ & $32(49.23)$ & \multirow{3}{*}{0.539} & 1.694 & 1.947 \\
\hline Women & $7(10.77)$ & $19(29.23)$ & & 1.548 & 1.913 \\
\hline \multicolumn{5}{|l|}{ Parent's Education } & \\
\hline High & 7 (10.77) & $27(41.53)$ & \multirow[t]{3}{*}{0.845} & 1.651 & 1.937 \\
\hline Low & 7 (10.77) & $24(36.93)$ & & 1.618 & 1.930 \\
\hline \multicolumn{5}{|l|}{ Household Income } & \\
\hline $\begin{array}{l}>2,515,000 \text { IDR }(>\$ 176,88) \\
<2,515,000 \text { IDR }(<\$ 176,88)\end{array}$ & $\begin{array}{l}5(7.70) \\
9(13.84)\end{array}$ & $\begin{array}{l}16(24.61) \\
35(53.85)\end{array}$ & 0.757 & $\begin{array}{l}1.563 \\
1.671\end{array}$ & $\begin{array}{l}1.961 \\
1.920\end{array}$ \\
\hline \multicolumn{6}{|l|}{ Clinical Symptoms } \\
\hline $\begin{array}{l}\text { kwashiorkor } \\
\text { marasmus }\end{array}$ & $\begin{array}{l}1(1.54) \\
13(20)\end{array}$ & $\begin{array}{c}1(1.54) \\
49(75.38)\end{array}$ & \multirow[t]{2}{*}{0.537} & $\begin{array}{c}-4.583 \\
1.686\end{array}$ & $\begin{array}{l}7.853 \\
1.895\end{array}$ \\
\hline marasmus + kwashiorkor & 0 & $1(1.54)$ & & & \\
\hline
\end{tabular}

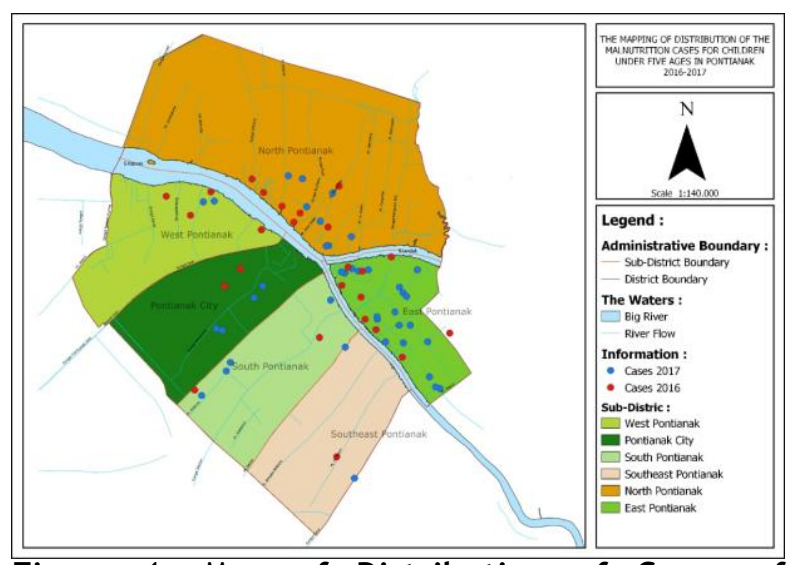

Figure 1. Map of Distribution of Cases of Malnutrition for Under Five Children by District in Pontianak City in January-December 20162017

\section{DISCUSSION}

Nutrition has profound effects on health throughout the human life course and is inextricably linked with cognitive and social development, especially in early childhood ${ }^{15}$.
Figure 1 below depicts the distribution of children's malnutrition cases aged 0-59 months according to districts in the city of Pontianak in 2016-2017 ${ }^{16,17}$

It can be seen in figure 1 that the district that recorded the most cases was East Pontianak SubDistrict by 29 cases $(44.6 \%)$. Of these cases, 9 cases were documented in 2016, and 20 of them were 2017. In fact, this sub-District was the smallest area in Pontianak City with the highest population density of $10,622 / \mathrm{km}^{2}$. Also, East Pontianak sub-District was recorded to have more primary health centers than other sub-districts. Thus, it should be easier for parents of the toddlers to obtain health services. Data from the health center (locally known as Puskesmas) revealed that many toddler's parents came from poor families with low incomes because the majority of the parents worked as daily laborers and housewives.

This is related to the ability of households to provide food that is determined by economic factors. This result is in accordance with research 
conducted by Suiraoka et al (2011) on poor and non-poor families in northern Denpasar District. The research highlighted the results of their analysis which showed that there were differences in the nutritional status of children under five in poor and non-poor families ${ }^{18}$. This difference can be caused by various factors such as direct causes, namely in under-fives of poor families, nutrient intake is lower compared to toddlers of nonpoor families. Besides, poor families might have poor sanitary conditions resulting in infectious diseases.

Table 4. Distribution of the number of malnutrition cases in 2016-2017

\begin{tabular}{lcccc}
\hline \multicolumn{1}{c}{ Districts } & In 2016 & \multicolumn{2}{c}{ In 2017 } \\
\cline { 2 - 5 } & $\mathrm{N}$ & $\%$ & $\mathrm{~N}$ & $\%$ \\
\hline City of Pontianak & 2 & 8 & 4 & 10 \\
West Pontianak & 4 & 16 & 2 & 5 \\
South Pontianak & 2 & 8 & 5 & 12.5 \\
North Pontianak & 7 & 28 & 8 & 20 \\
East Pontianak & 9 & 36 & 20 & 50 \\
Southeast Pontianak & 1 & 4 & 1 & 2.5 \\
\hline Total & 25 & 100 & 40 & 100 \\
\hline
\end{tabular}

Following this, this research presents the distribution of malnutrition cases in Pontianak City from 2016-2017 based on the sequence of regions or districts, from the highest number of malnutrition cases to the lowest. First of all, East Pontianak District was noted to have the highest number of malnutrition cases (29 cases). The district was then followed respectively by North Pontianak District (15 cases), South Pontianak District (7 cases), Pontianak City District $(6$ cases), West Pontianak District (6 cases), and Southeast Pontianak District (2 cases).

The distance of the house to utilize health services can be divided into three groups, close distance if calculated within a radius of $<1 \mathrm{~km}$, moderate if the location is within $1-4 \mathrm{~km}$, and the outreach if it was more than $4 \mathrm{~km}^{19}$. The results of the study pointed out that Pontianak City had 23 Puskesmas. The closest distance to the place where malnutrition was found and the health facility was $<1 \mathrm{~km}$. There were still cases of malnutrition, including the Puskesmas of Kampung Dalam, Puskesmas Perumnas I, Puskesmas Banjar Serasan, Puskesmas Parit Mayor, Puskesmas Siantan Tengah, Puskesmas Siantan Hilir, Puskesmas Alianyang, Puskesmas Gang Sehat, Puskesmas Saigon, Puskesmas Paris II, Puskesmas Perum II, and Puskesmas Tanjung Hulu. Although there were still cases of malnutrition close to the health centers, the factor was more about the family's economic conditions that did not support to access the healthcare service. They were unable to admit their children to the hospital. Disruption of the economic situation will disrupt the accessibility of the community and family to health services, for example, immunization services, care related to growth, morbidity, and mortality of children ${ }^{20}$

Figure 2 shows the standard distance of malnutrition cases in Pontianak City. The standard distance for malnutrition cases reported was an area of $29 \mathrm{sq} \mathrm{km}$ with spatial mean center coordinate was $315805(\mathrm{X})$; $9996719(\mathrm{Y})$. This analysis shows that both years develop a minor difference of malnutrition distribution cases with smaller dispersal of standard distance in the year 2016 compared to 2017.

Figure 3 indicated that malnutrition cases displayed a clustered pattern in 2016. The results of the ANN suggested that the pattern of malnutrition cases in 2016 was clustered. The ANN was 0.748551, the z-score was -3,042362, and the $p$-value was 0.002347 . The critical value (z-score) was both less than -2.58 and -1.96 . It suggests that there is less than a 1 percent likelihood that the clustered pattern is significant. However, in 2017, the results of the ANN suggest that the pattern of malnutrition cases was dispersed. The ANN was 1,741567, the z-score was 5,115087, and the p-value was 0.000000 . There was a less than $1 \%$ likelihood that this dispersed pattern could be the result of a random chance.

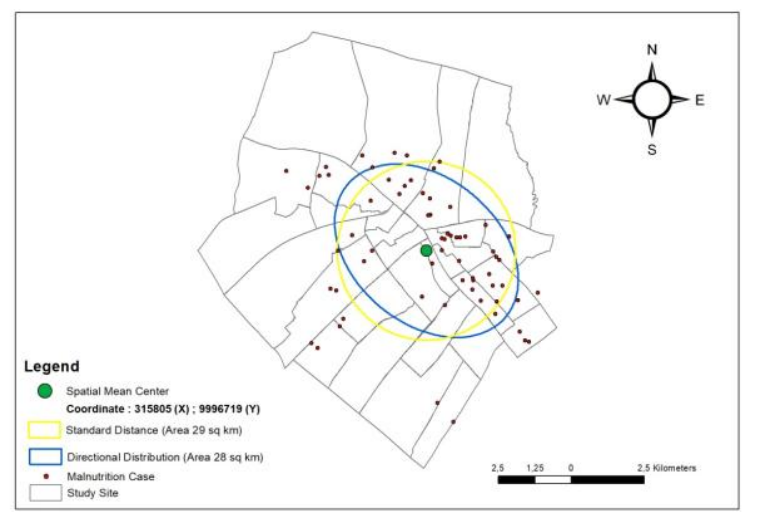

Figure 2. Map of Distribution of Malnutrition for Under Five-year-old Children by Districts in Pontianak City during 2016-2017 

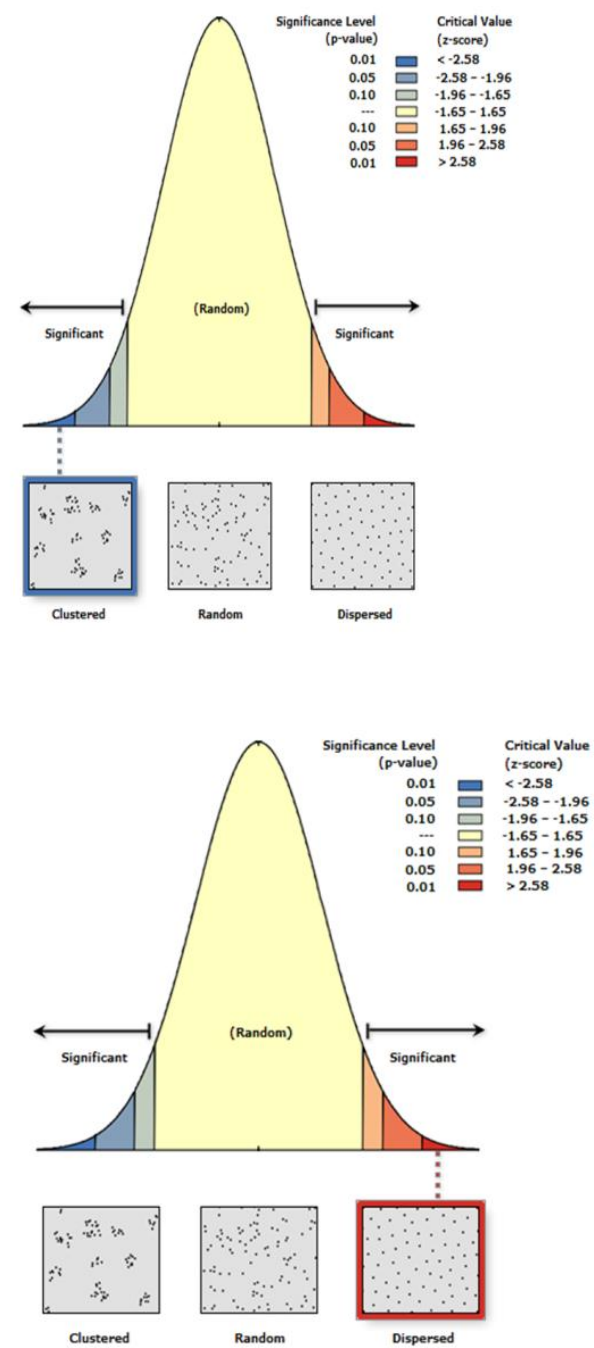

Figure 3. Spatial patterns of malnutrition cases in the years of 2016 and 2017
Table 5 summarized the nearest distance method analysis. Z-score reading shows that pattern of less than $1 \%$ likelihood was significant. According to theory, when the index (average nearest neighbor ratio) is less than 1 , the pattern shown is clustered ${ }^{10}$. Meanwhile, if the index is bigger than 1, the pattern direction is dispersed. Thus, the distribution pattern of malnutrition cases reported in this study is dispersed. Z-score reading is bigger than $1 \%$ indicates the distribution pattern of malnutrition cases is significant. Our findings showed that the prevalence of malnutrition in children under 5 years old was clustered in 2016 and dispersed in 2017. The results of studies by Hasan et al. (2018) in Bangladesh ${ }^{21}$, Gebreyesus et al. (2016) in Ethiopia ${ }^{22}$ and Khan and Mohanty(2018) in India ${ }^{24}$ were also in line with our study. Their study indicated that children identified in a cluster were at risk (stunted and wasted children) more than four times the ones outside the cluster ${ }^{22}$. However, the results of the studies by Varghese et al. (2019) in India showed that there was no evidence of cluster formation ${ }^{23}$.

\section{Study Limitation}

This study has several limitations that can affect research results. First, this study only examined socioeconomic conditions while other factors related to comorbidities and maternal conditions were not examined. We were also unable to investigate potential risk factors, such as parental work or health literacy, due to a lack of access to the data. In addition, we failed to assess the prevalence of malnutrition based on gender and religion. This limitation can be used as an evaluation and can be refined by further researchers who are interested in investigating this research area.

Table 5. The spatial pattern for Malnutrition cases in Pontianak City.

\begin{tabular}{|c|c|c|c|}
\hline $\begin{array}{l}\text { Years of Malnutrition Cases } \\
\text { Reported }\end{array}$ & Nearest Neighbor Ratio & z-Score & $p$-Value \\
\hline $\begin{array}{l}2016 \\
2017\end{array}$ & $\begin{array}{l}0.748551 \\
1.741567\end{array}$ & $\begin{array}{r}-3.042362 \\
5.115087\end{array}$ & $\begin{array}{l}0.002347 \\
0.000000\end{array}$ \\
\hline
\end{tabular}

\section{CONCLUSION}

Spatial statistical distribution and pattern analyses play important roles in understanding malnutrition cases epidemiology in the study area. This is because distribution and spatial patterns are derived from certain processes. These three spatial statistical analyses (spatial mean center, standard distance, and directional distribution) show that the malnutrition cases in the years of 2016 and 2017 were clustered and dispersed at the east of the study site. This analysis found that there were differences between the direction of malnutrition cases distribution, although it was minimal. Pattern distribution analysis was conducted to enhance the finding results and it was found that the clustered pattern was dominant in this study area with an average nearest neighbor ratio of less than 1. This indicates that there is a factor affecting the rise in malnutrition cases reported in the year 2016 compared to 2017. Above all, this shows that spatial modeling should take into account of malnutrition cases reported in other years for further studies. We observed that the household population in this eastern region of Pontianak City was live in poverty, which may be contributing factors in the malnutrition cases. 


\section{ACKNOWLEDGMENT}

The authors would like to acknowledge to Pontianak City Health Office for supporting this research. We further thank the Head of Primary Health Care in Pontianak City for their support and tolerance during the study. We also thank the Faculty of Medicine Universitas Tanjungpura for funding this study.

\section{REFERENCES}

1. National Board of Health Research and Development. Basic Health Research (Riskesdas 2010). Jakarta: Ministry of the Health Republic of Indonesia. 2010.

2. West Kalimantan Health Office. West Kalimantan Province Health Profile 2017. Pontianak; West Kalimantan Provincial Health Office. 2018.

3. Achmadi UF. Public Health Theory and Application. Jakarta: Raja Grafindo Persada. 2013.

4. Hardiansyah. Supariasa, IDN. Nutrition Theory \& Application. Jakarta: EGC Medical Book. 2016

5. RI Ministry of Health. Indonesia Health Profile 2017. Jakarta: RI Ministry of Health; 2018.

6. West Kalimantan Health Office. West Kalimantan Province Health Profile 2017. Pontianak; West Kalimantan Provincial Health Office. 2018.

7. Murni Su, Syahrul HB, et al, Risk Mapping of Malnutrition Distribution using Remote Sensing and Geoinformation System (GIS) in Tumpat, North of Kelantan, Conference: MAP ASIA, Jakarta, 2005

8. Ali Almasi, Alireza Zangeneh, Sahram Saeidi, et al. Study of the Spatial Pattern of Malnutrition (Stunting, Wasting and Overweight) in Countries in the World Using Geographic Information System, International Journal of Pediatrics, 2019, 7, 1026910281

9. E. Mohammed, Remote Sensing and Geographical Information System to map environmental factors associated with Children Malnutrition Severity in Khartoum State, Sudan, environmental epidemiology, 2019, $3, \mathrm{p} 273$

10. ESRI. 2019. Available online: https://pro.arcgis.com/en/pro- app/tool-reference/spatial-

statistics/an-overviewof-the-spatialstatistics-toolbox.htm (accessed on 6 August 2019).

11. Reshadat S, Zangeneh A, Saeidi S, Izadi N, Ghasemi SR, Rajabi-Gilan N. A Feasibility Study of Implementing the Policies on Increasing Birth Rate with an Emphasis on Socio-economic Status: A Case Study of Kermanshah Metropolis, Western Iran. Social Indicators Research. 2018:1-18.

12. Cromley E, McLafferty S. Public participation GIS and community health. GIS and public health. 2012:411-22.

13. Alexandersson, A. Graphing confidence ellipses: An update of ellip for Stata 8. Stata J. 2004, 4, 242-256. [CrossRef]

14. Sabrina Marx, Revati Phalkey, Clara B Aranda-Jan, et al. Geographic information analysis and web-based geoportals to explore malnutrition in Sub-Saharan Africa: a systematic review of approaches, BMC Public Health 2014, 14:1189.

15. Black RE, Victora CG, Walker SP, Bhutta ZA, Christian P, De Onis M, et al. Maternal and child undernutrition and overweight in low-income and middle-income countries. The lancet. 2013;382(9890):427-51

16. Pontianak City Health Service. Profile of Pontianak City Health Office, 2017.

17. Pontianak City Health Service. Profile of Pontianak City Health Office, 2018.

18. Suiraoka P, Sukraniti PD, Gumala YMN. Differences in Nutritional Status, Feeding Patterns, and Toddler Parenting in Poor and Non-Poor Families in the District of North Denpasar, Denpasar City. Journal of Nutrition. 2011; 2 (2): 83-92.

19. Razak, A. Utilization of Coastal Community Health Services, Kalammedia Pustaka, Makassar, 2000.

20. Sartika, R.A.D. Analysis of the Utilization of Health Services Program for Toddler Nutrition Status. National Journal of Public Health Vol. 5 No. October 2, 2010, page 80. 2010.

21. Hasan MT, Mamun AA, Williams GM, Magalhães RJS. Spatiotemporal 
heterogeneity of malnutrition indicators in children under 5 years of age in Bangladesh, 1999-2011. Public health nutrition. 2018;21(5):857-67.

22. Gebreyesus SH, Mariam DH, Woldehanna T, Lindtjørn B. Local spatial clustering of stunting and wasting among children under the age of 5 years: implications for intervention strategies. Public health nutrition. 2016;19(8):1417-27.

23. Varghese JS, Stein AD. Malnutrition among women and children in India: limited evidence of clustering of underweight, anemia, overweight, and stunting within individuals and households at both state and district levels. Am J Clin Nutr. 2019 Apr 1;109(4):1207-1215.

10.1093/ajen/nqy374

doi: 